\title{
Espaços de sociabilidade na América Portuguesa e historiografia brasileira contemporânea*
}

\section{Spaces of sociability in Portuguese America and contemporary Brazilian historiography ${ }^{\star *}$}

\author{
CAIO C. BOSCHI \\ Departamento de História/PUC-MG \\ Av. Dom José Gaspar, 500 Coração Eucarístico - Belo Horizonte/MG, CEP 30535-901 \\ caioboschi@hotmail.com
}

\begin{abstract}
RESUMO Este texto,originariamente destinado a uma palestra, apresenta visão panorâmica, de cunho impressionista e ensaístico, para público pouco familiarizado com a História do Brasil, a respeito da produção acadêmico-científica realizada nas últimas duas décadas sobre os espaços de sociabilidade na América Portuguesa. Reportando-se, a título ilustrativo, a obras e autores dedicados ao tema, faz também referência a exemplos de lacunas historiográficas que reclamam estudos.
\end{abstract}

Palavras-chave Historiografia, espaços de sociabilidade, América Portuguesa

\footnotetext{
Texto da palestra proferida na sessão de abertura das IX Jornadas de História Ibero-Americana, promovidas pelo Instituto de Cultura Ibero-Atlântica (ICIA), em Portimão (Portugal), entre 8 a 10 de maio de 2003.
}

** Artigo recebido em 01/03/2006. Autor convidado. 
ABSTRACT This article, originally intended as a lecture, presents for those readers that are not too familiarized with the history of Brazil an impressionistic and essayistic comprehensive view of the academic-scientific production during the past two decades that investigates the spaces of sociability in Portuguese America. For illustration sake, the article refers to authors and works that investigate this topic and also alludes to historiographic gaps that call for further study.

Key words Historiography, spaces of sociability, Portuguese America

Por historiografia brasileira contemporânea refiro-me aqui tão-somente à produção de autores brasileiros nos últimos vinte anos. O marco cronológico adotado não é ortodoxo. Sua escolha traz dificuldades, a mais flagrante das quais - em nada original — é a da inexistência de fontes para consulta, seja quanto à sistematização de dados, seja com relação a análises interpretativas, seja ainda pela propalada escassez de críticas bibliográficas sobre a temática da historiografia no Brasil. Por isso, optei por conferir caráter impressionista e ensaístico a essas notas. Meras e incompletas indicações, sem qualquer intuito analítico.

À semelhança de Falcon e experimentando idênticas agruras com as quais ele se debateu ao elaborar, há quinze anos, "ensaio histórico-interpretativo" sobre a produção historiográfica portuguesa contemporânea, é mister, desde logo, conceituar historiografia. Retorno ao autor, dele retiro e incorporo a definição: "historiografia para nós [...] deverá ser entendida mais no seu sentido terra-a-terra, de conjunto de obras produzidas e reunidas segundo um pressuposto mais ou menos consensual - o de serem trabalhos tidos e havidos como sendo de história - , do que no sentido de análise sistemática dos pressupostos epistemológicos subjacentes à própria atividade historiográfica, entendida como o processo mesmo de produção do conhecimento histórico" (FALCON, F.J.C. 1988, p. 82).

Inicio com afirmativa consensual, dizendo que a historiografia brasileira ganhou fôlego e novos contornos a partir da década de 1970, por razões que, sucinta e parcialmente, serão a seguir esboçadas. (BEZERRA, H.G., 1996; BOSCHI, C.C., 1995, 1999; CAPELATO, M.H.R., 1995; FICO, C.; POLITO, R., 1992, 1996; LAPA, J.R. do A., 1985; NOVAIS, F.A., 1990; SAMARA, E.M., 2002; WEHLING, A., 2000).

Ainda à partida quero reiterar a noção primária de que o estudo da historiografia não pode estar dissociado da análise do momento e da realidade histórica nas quais ela se realiza, ainda que tenha presente que a disseminação social do conhecimento possa ocorrer não coincidentemente com o instante da sua produção. E que a análise da produção não prescin- 
da das condições da sua reprodução, circulação, consumo e crítica (FICO, C.; POLITO, R., 1992, p.19). Assim, anuncio que meu marco cronológico inicial tem no horizonte o contexto brasileiro de meados dos anos 80 da centúria cessante.

Na altura, os constrangimentos até então impostos pela ditadura militar iam se desanuviando. No âmbito universitário, as exigências de titulação acadêmica formal forjavam o advento de produção científica não apenas de maior vulto como de melhor qualidade. A profissionalização do historiador ganhava corpo, de um lado, por meio da adoção de novos parâmetros e paradigmas científicos; de outro, pela busca de maior e mais sólido respaldo para os argumentos explicativos, com mergulho mais fundo e abrangente nos acervos documentais do País e fora dele.

Em simultâneo, assistia-se, no Brasil, a verdadeiro boom na difusão e no revisionismo do conhecimento histórico, seja pela publicação de livros, seja pelo surgimento de novas revistas especializadas, seja pela proliferação de teses e dissertações.

A chamada crise do marxismo fez com que a historiografia brasileira, gradativamente, fosse se desvencilhando dos esquematismos e das ortodoxias marxistas e estruturalistas vigentes. Temas-objeto da História Social, como a História do Trabalho, dos movimentos sociais (especialmente a do movimento operário) e revolucionários (quer da fase colonial, quer da republicana) que, justificavelmente, tinham forte incidência, passaram a conviver com temas da chamada História Cultural, nesta incluídos — sem que possamos discerni-los - estudos sobre mentalidades, sentimentos, imaginário, representações, identidades, família e gênero. Análises estruturais cedem lugar e vez a pesquisas sobre microfenômenos.

Um último apontamento preliminar procura justificar o recorte temático. Restringir minha apresentação ao período colonial tornou-se (também) contingência natural, tendo em vista tanto os limites impostos ao texto, como o desconforto em aventurar-me por contextos históricos, fontes e bibliografias com as quais não tenho familiaridade.

Optando por conter minhas observações à História do Brasil-Colônia, eximo-me de entrar no mérito de realidade social consideravelmente contrastante com a da etapa aqui privilegiada. Soa-me despiciendo recordar, dando azo à imaginação, as mudanças que advieram e se configuraram, quando, a partir de janeiro de 1808, o Brasil tornou-se sede da monarquia portuguesa.

Nesse novo momento sim, encontramos matéria e fontes em profusão para o estudo das práticas e dos espaços de sociabilidade, a começar pelas óbvias e amplas repercussões da instalação da Corte na cidade do Rio de Janeiro. Em contrapartida, outros são os referenciais teórico-metodológicos e analíticos requeridos. 


\section{A Colônia na historiografia brasileira}

Não é novidade que os estudos sobre o período colonial ocuparam, desde há, pelo menos, trinta anos, lugar secundário na preferência dos historiadores brasileiros. Até 1979, ele abarcava 13\% do total dos trabalhos produzidos e publicados, comparativamente a $41 \%$ respeitantes ao Império e a $46 \%$ dos que tiveram a República brasileira como momento de opção temática. (FALCON, 1997, p. 87). Na década de 1980, 835 teses e dissertações foram escritas para efeito de livre-docências e nos cursos de Doutorado e Mestrado em História no Brasil, cabendo a primazia às temáticas voltadas para a História Social, enquanto 85\% dos textos enfocavam a História do País. Nesse universo, reiteravam-se os índices apurados para os anos precedentes; se a Colônia foi abordada por 14,1\% dos autores, o Império absorveu praticamente o dobro dos trabalhos, isto é, $26,6 \%$; mantendo-se a República como período preferencial, com acentuado crescimento, ao atingir o patamar de 59,3\% (FICO, C.; POLITO, R., 1992, p. 53).

Igual tendência se manifesta nos dados estatísticos concernentes aos artigos veiculados em periódicos especializados da área de História editados no Brasil, no período. Demais, a perspectiva não se altera, ao se contabilizar, nos catálogos das editoras brasileiras, os títulos de obras por elas publicados: 40\% deles dizem respeito à História do Brasil, de cujo total $22,7 \%$ se referem a assuntos coloniais, 6,2\% se situam na interseção Colônia-Império, 24,9\% têm o Império como objeto, 3,6\% compreendem Império-República e 42,7\% são especificamente relativos à fase republicana brasileira (FICO, C.; POLITO, R., 1992, p. 135-136).

Interessante assinalar também que os responsáveis pela apuração dessas informações, ao analisá-las, chamam a atenção para as ausências de certos temas ou objetos naquele conjunto historiográfico, asseverando que "pouco se fez em temas como o da estratificação social, da composição dos grupos e classes sociais [...] pouco se estudou também do comportamento cultural dos diversos segmentos sociais, aspecto importante em um país imerso numa profunda diversidade de crenças, valores, hábitos e padrões de gosto" (FICO, C.; POLITO, R., 1992, p. 58-59).

De qualquer das maneiras, é indiscutível o progresso da pesquisa histórica no Brasil, sendo uníssona a avaliação de que, desde aqueles tempos, a investigação na área tenha se consolidado e se profissionalizado. A ressalva desse último aspecto não significa necessariamente o advento ou a fixação de historiadores habilitados e qualificados à "compreensão das interconexões entre as várias instâncias" do processo histórico (COSTA, E.V. da, apud MORAES, J.G.V. de; REGO, J.M., 2002, p.89; MALERBA, J., 2002).

A exemplo de suas congêneres, a historiografia brasileira desses últimos anos esteve/está exposta a enovelar-se no estudo das descontinuidades, das minudências e dos detalhes, em detrimento da apreensão do sentido 
fulcral dos fenômenos históricos e das imprescindíveis tentativas de realização de trabalhos de sínteses.

Em compensação, a pesquisa arquivística adquiriu notável dimensão e incorporou-se como postura corriqueira na conduta dos estudiosos da História do Brasil, seja, por exemplo, pela consulta a fundos e acervos até aquela altura pouco compulsados de maneira sistemática e vertical (como a documentação dos arquivos notariais e eclesiásticos), já pela aplicação de técnicas de coletas mais sofisticadas de dados (com desenvolto uso da Informática), já pelo melhor e mais afeito domínio de atualizada literatura teórico-metodológica das ciências políticas e sociais, mormente aquelas que se fixam nas afinidades da História com a Antropologia e a Etnografia.

Vejamos, pois, como tem sido exercitada a produção científica sobre o Brasil Colonial, quando se constata, neste ano de 2003, a existência de 28 cursos de Mestrado e 19 de Doutorado em História com funcionamento regular e, principalmente, reconhecimento oficial.

Alguns trabalhos têm procurado realizar a inventariação dos livros publicados nos últimos anos (SAMARA, E.M., 1999) ou, conforme explicitado nos próprios títulos, têm examinado a recente produção historiográfica brasileira do período (CARDOSO, C.F.; VAINFAS, R., 1997; FREITAS, M.C., 2001).

Por estarmos no interior e sob os auspícios de instituição que congrega estudiosos de diferentes nacionalidades, permitam-me recordar iniciativas e esforços desenvolvidos no sentido de se promover melhor conhecimento recíproco entre a historiografia brasileira e a portuguesa, inclusive com vistas a possíveis implementações de trabalhos conjuntos (ARRUDA, J.J.; FONSECA, L.A. da, 2001; ARRUDA, J.J.; TENGARRINHA, J. M. 1999; COUTO, J., 1993; TORGAL, L.R. et al, 1996, p.345-361).

\section{As sociabilidades na historiografia colonial}

O estudo das sociabilidades, a despeito de sua tardia evidência, não constitui inovação no quadro da atual historiografia brasileira. Poupando-me de retrogradar em demasia e atendo-me a autores já ditos clássicos, registre-se a abordagem da temática, por exemplo, na trilogia maior de Gilberto Freyre relativa à análise da sociedade brasileira, sobretudo em Casa Grande e Senzala. Ali, os historiadores absorve(ra)m não só sugestões de temas, noções básicas da antropologia cultural norte-americana, mas, também, categorias analíticas como a de mestiçagem cultural, geradora de vastos debates de natureza teórico-metodológica, sem embargo de ser noção nuclear para os textos que se lhe seguiram. Noção cuja complexidade pode levar ao paradoxo de se entender, como o fez Fernando Novais, que a miscigenação foi, "ao mesmo tempo, um canal de aproximação e uma forma de dominação, um espaço de amanciamento e um território de enrijecimento do sistema". (NOVAIS, F.; MELLO E SOUZA, L. de. 1997, p. 28). 
É bem verdade que, inaugurada pela escola sociológica paulista, tendo à frente Florestan Fernandes e secundada, dentre outros, por seus discípulos Fernando Henrique Cardoso e Octávio lanni, a crítica à obra gilbertiana impregnou a historiografia brasileira contemporânea.

Todavia, o fato de o tema da sociabilidade na historiografia brasileira contemporânea ter sido e estar sendo trabalhado por outros cientistas sociais, e não predominantemente pelo historiador, revela, quando nada, que, hoje, felizmente a meu ver, não há campo de atuação rígido, que o objeto da História não pode ser delimitado, não há divisão social do trabaIho intelectual. Destarte, é a abertura, cada vez maior, do historiador para a multidisciplinaridade, para que ele introjete as ciências sociais e construa o instrumental para seus trabalhos, a abertura, em suma, para outros horizontes explicativos que infundem vigor e interesse pelo conhecimento histórico (FENELON, D. R. 1992).

Felizmente tudo faz crer que, já agora, a historiografia em causa vai superando a ausência ou a dificuldade de diálogo com outros cientistas sociais. Parece-me, assim, que não mais se aplica a avaliação de Déa FeneIon, feita há pouco mais de uma década: "para se ter a certeza e a verdade precisa-se sempre desqualificar o outro, pois só assim se caminhará na direção daquilo que se convencionou chamar, abstratamente, de perspectiva crítica, ou de transformação social, ou de mudança. Cresce-se pouco quando em contato com outro tipo de produção ou posição diferente da nossa, conseguimos apenas desqualificá-la como não tendo as qualidades exigidas por nosso modelo de vida ou de trabalho intelectual. Isto nos desobriga de pensar outras possibilidades históricas, inseridas no real, tanto quanto as nossas e, ainda mais, impede o diálogo porque não reconhece o outro como sujeito possível de um conhecimento diferente mas, de forma nenhuma, menos válido." (FENELON, D. R. 1992, p. 8).

A notar, ainda, que o surgimento de trabalhos sobre sociabilidades na historiografia brasileira contemporânea acontece em momento no qual se encontra em causa não apenas a dita fragmentação da historiografia, mas também, e em particular, a fragmentação da própria identidade do historiador (FALCON, F.J.C., 1996, p.7-30, especialmente p.13-17).

Guardadas as reservas às afirmativas generalizantes, pode-se dizer que há certa tendência interpretativa da historiografia brasileira em abordar as sociabilidades na América portuguesa como fenômeno essencialmente social, esquecendo-se de que a sociedade de então não se abstraía dos ditames infligidos — e nem sempre na prática observados, é verdade, — do Estado absolutista português. Seja como for, não obstante a inconsistência em se apontar qual o viés determinante — se é que ele existe - , cumpre assinalar que, na base de todas as relações sociais a elas subjacentes, avultam as diretrizes estatais do Reino. 
Compreender os espaços de sociabilidade na esfera da história política não significa, porém, conferir ao Estado absolutista condição sobranceira sobre o corpo social (SCHWARTZ, S., 2003, p. 303). As práticas, as ações e os comportamentos dos indivíduos e dos grupos sociais não podem estar - e não estiveram - redutoramente atrelados e dependentes da vontade do Estado, como, por vezes, a historiografia faz supor. Reportemo-nos às palavras de Maria Odila Dias que, embora se referindo a outra etapa da história brasileira, conclama: "é preciso elaborar questões que façam falar as fontes e procurar nos documentos, interpretar as vozes das pessoas que viveram e vivem fora da cidadania tal como é constituída entre nós. Para que o historiador possa interpretar suas vozes e as condições de sobrevivência e de sociabilidade em que viveram, ele tem de abdicar de ter o Estado brasileiro como sujeito central da nossa história, assim como tem de abandonar conceitos generalizantes tributários de ideologias de dominação." (DIAS, M.O.L. da S., apud MORAES, J.G.V. de; REGO, J.M., 2002, p. 204-205).

Na Colônia, não houve simples reprodução das formas e dos espaços de sociabilidade vividos na Metrópole, ainda que nela, compreensivelmente, inspirados. Na América, as transplantações reclamaram e adquiriram cor local e, em razão, remodelaram-se, sem que aqui se esteja fazendo abstração das manifestações que emergiram inovadoramente no outro lado do Atlântico.

Orientando-se por abordagens unilaterais, por vezes com nítido traço maniqueísta, o historiador das sociabilidades no Brasil, conscientemente ou não, tem se envolvido na estéril e falaciosa discussão respeitante à hegemonia entre os estudos micro-históricos contrapostamente aos de natureza macro. Atitude comprometedora, acima de tudo, porque o mais elementar bom senso indica o sentido de complementaridade (e não de excludência) entre as abordagens. São "apenas modos distintos de conceber a História e de fazer História", tão-somente "diferentes escalas ou ponto de observação" (VAINFAS, R. In: CARDOSO, C.F.; VAINFAS, R. 1997, p.448).

Ademais, é preciso lembrar que, embora não seja exclusividade da historiografia brasileira, a escassez de reflexões teóricas em torno do nosso campo de conhecimento remete-nos a buscar subsídios e sustentação nas outillages próprias de outras ciências sociais, o que, a bem dizer, tem resultado em benefício qualitativo para os trabalhos historiográficos. A empiria predominante fica, pois, abrigada e preservada pelo lastro teórico advindo das ciências sociais, proporcionando maior teorização da História (NOVAIS, F.A., 1990, p. 113).

Para o caso específico do estudo das sociabilidades, são de variada procedência - por vezes, fundindo-os e fazendo-se convergir entre si — os aportes teórico-metodológicos que os historiadores, cultivando a interdisciplinaridade, incorporam com vistas à operacionalização de suas investi- 
gações (VOVELLE, M., 1987). Assim é que, por exemplo, se nos estudos pioneiros eram a Sociologia e secundariamente a Política a abrirem as portas para os trabalhadores das oficinas da História das sociabilidades, já agora é da Antropologia e da Etnografia que procedem as categorias analíticas e o aparato teórico-metodológico de que o historiador se apropria.

Releve-se a forte influência exercida por autores italianos, norte-americanos e ingleses na historiografia brasileira respeitante à História Cultural, quebrando, assim, indiscutível hegemonia (quando não exclusividade) da historiografia francesa. Foucault é dos poucos franceses que perfilam entre as matrizes e os autores inaugurais da História Cultural no Brasil, território em que E. P.Thompson e Carlo Ginzburg deitaram sólidas raízes.

A notar, também, e curiosamente, o silêncio da historiografia brasileira relativamente ao livro seminal de Maurice Agulhon. Por oposição às obras de M. Bakhtin, de Norbert Elias, de Kantorowicz e de J. Habermas, que tiveram tradução e têm dilatada circulação nos meios acadêmicos brasileiros, o Pénitents et francs-maçons de l'ancienne Provence: essai sur la sociabilité méridionale permanece sem tradução para a língua portuguesa; quando muito é referido e quase nunca lido pelos historiadores brasileiros. Não se percebe qual tem sido o aproveitamento que tais investigadores fazem ou fizeram do clássico texto francês, ainda que fosse para rechaçá-lo ou para apontar a inadequação ou a impropriedade de seu uso ou de sua inspiração para a análise da problemática histórica colonial brasileira.

Seja como for, convém ter em mente a escassez de bibliografia específica, ou melhor, aquela explicitamente relativa às sociabilidades no âmbito da historiografia sobre o passado colonial brasileiro. Entre nós, não há nenhuma análise, idêntica àquela que, com verticalidade e penetrante análise, Maria Alexandre Lousada (1995), aqui presente, realizou sobre Lisboa. A essa constatação poder-se-ia aduzir uma série de observações restritivas para reforçar a condição rarefeita da temática no escopo em foco. Tomemos um exemplo. Embora, evidentemente, não seja critério científico para a apuração de dados dessa natureza, o exame em catálogos de editoras e das bibliotecas, nas bibliografias inseridas em obras especializadas sobre o período em consideração, resultará na identificação de poucos títulos específicos sobre sociabilidades e os seus espaços.

Na realidade, a temática dessas Jornadas está subtendida em apreciável número de obras, artigos, teses, dissertações e comunicações da historiografia brasileira recente. É o que se observa naquela que pode ser considerada a mais expressiva obra, nos últimos anos, no campo do objeto-tema em pauta. Refiro-me a Festa: cultura e sociabilidades na América Portuguesa, organizada por István Jancsó e Íris Kantor, compilando, em dois alentados volumes, as cinqüenta comunicações que foram apresentadas em congresso, com igual denominação, promovido no ano de 2000 pela Universidade de São Paulo (JANCSÓ, I.; KANTOR, Í., 2001). A destacar 
que, de um lado, os colaboradores eram predominantemente historiadores, incluindo alguns de nacionalidade portuguesa; de outro, literatos, musicólogos e os autores com formações acadêmicas distintas, todos conferindo enfoque essencialmente histórico aos seus trabalhos.

Com efeito, as festas têm sido objeto de particular predileção dos estudiosos brasileiros, no que tange às manifestações de sociabilidade. Nesse particular, mencione-se que a produção historiográfica brasileira sobre elas tem atribuído realce aos aspectos exibicionistas, espetaculosos e exuberantes dos eventos. Poucos são os textos que, explorando o caráter frenético e alienante das festas, busca apreender e analisar a ideologização nelas contida e por elas expressa. Citem-se, à guisa de ilustração, a dissertação de Mestrado de Íris Kantor e os textos de Rodrigo Bentes Monteiro e Luciano Raposo Figueiredo, em que o viés político subjacente às festas constitui ponto fundamental de análise. Em Monteiro e em Figueiredo, por exemplo, o embricamento entre ocasiões de júbilo coletivo, revoltas e motins e relações do poder régio lusitano explicita-se como fulcro da abordagem (JANCSÓ, I.; KANTOR, Í. 2001, p.146 e 276). À luz da interpretação de Affonso Ávila, Kantor debruça-se sobre o sentido do pacto festivo (KANTOR, Í. 1996), ao tempo em que Del Priore, na esteira de Maravall e a partir da relação simbiótica Estado-Igreja, dedica-se às festas coloniais como prática do crescente poder do absolutismo português e, em paralelo, como evidências de "brechas de resistências, transculturalidades e utopias" (DEL PRIORE, M. 1994, p. 15 e 27). Em outras palavras, nota-se nítida percepção, pelos autores, do papel de descompressão das tensões sociais e, por conseguinte, de preservação do sistema colonial exercido pelas festas naquela realidade histórica.

Em resumo, constata-se a existência, no Brasil atual, de relevante historiografia sobre as festas na sua condição de espaço e tempo de libertação dos jugos e das restrições do Antigo Sistema Colonial. Daí, os compreensíveis excessos e transgressões, de variada natureza, nelas perpetrados, comportamentos esses que, no mínimo, revigoraram e reafirmaram laços coletivos e comunitários.

Não obstante as festas serem tidas ou idealizadas como transplantação e representação do Império português nos seus domínios ultramarinos, o que se capta, sem estranhamento, é que elas adquiriram cor local, além de se terem realizado à parte das autorizações e das chancelas oficiais.

Como referido, na América portuguesa, no que respeita aos espaços oficiais, a sociabilidade festiva se fez espelhando-se nos parâmetros e por determinação metropolitanos, de que são vivos e ricos exemplos as festas e cerimônias religiosas, com particular destaque para as procissões de Corpus Christi. (SANTOS, B.C.C., 2001).

Praticamente não há estudos comparativos entre as procissões que se realizavam no Brasil Colonial. Esses trabalhos pouco ultrapassam o nível 
descritivo. Quando existem, tais comparações têm como parâmetro e referencial cerimônias congêneres celebradas na Metrópole. Ademais, outros espaços dos domínios ultramarinos portugueses não são contrastados nessa temática. Daí a impossibilidade de se interpretar ou mesmo projetar o significado e, sobretudo, a dimensão adquirida por esse substancioso fenômeno de sociabilidade no contexto histórico aqui considerado, sem esquecer a perspectiva diacrônica que essa análise demanda, tendo em vista as acentuadas diferenças entre as exuberantes procissões realizadas no Setecentos, quando cotejadas com as dos dois séculos anteriores. Esclareça-se, outrossim, que a ênfase conferida pela historiografia brasileira às procissões de Corpus Christi — inquestionavelmente a procissão de maior relevância e destaque social - tem ofuscado a análise de celebrações que, por não terem o caráter oficial daquelas, quando estudadas, certamente informarão aspectos essenciais não só das sociabilidades, como do próprio processo de estratificação social e do sentido político desses acontecimentos.

A incorporação de negros, mulatos e índios às festas, as quais não estiveram isentas de evidenciarem inerentes acréscimos culturais trazidos por esses grupos sociais, fez com que elas adquirissem conotação singular face às suas matrizes e modelos reinóis. Fossem elas festas promovidas e financiadas oficialmente, através das câmaras municipais (ex.: Corpus Christi, desposórios, nascimentos e óbitos na família real), fossem aquelas nascidas da vontade de determinados segmentos, sobre quem, nesses casos, naturalmente, recaíam, se não a totalidade, o fundamental dos gastos e a responsabilidade da promoção. Assim, a "festa unificava, mas também diferenciava." Nelas havia incluídos e excluídos. Mais. Mesmo entre os primeiros, há diferenças a apontar.

Na historiografia brasileira sobre a fase colonial, particular atenção tem sido conferida às festas urbanas. Nosso conhecimento das festividades rurais naquele período, cujo volume de trabalho é inferior ao anterior, ainda é adquirido por intermédio dos cientistas sociais, sobretudo dos antropólogos. Para ambas as realidades, quase sempre os trabalhos, analisando celebrações locais, induzem a entendê-las como uniformes e extensíveis a todos os quadrantes da Colônia. Tais equívocos metodológicos, naturalmente, distorcem a apreensão dos fenômenos em pauta.

Além disso, na análise de tais eventos, a tendência é a de englobá-los em conjunto único, não atentando, repito, para as relevantes diferenças entre espaços urbanos e espaços rurais, para peculiaridades regionais, para as diversidades das formações sociais, para o caráter circunstancial ou regular das mesmas, para as variabilidades advindas dos diferentes momentos históricos em que se realizaram e, como referido, para a sua condição original de serem promoções institucionalizadas ou de serem manifestações espontâneas da população. 
É salutar, porém, observar que trabalhos recentes têm apreendido essas singularidades, como no caso dos estudos sobre as associações laicas coloniais. Por ser um dos universos temáticos prediletos, observa-se nas monografias, dissertações e teses geradas nos cursos universitários alguma tendência à identificação das peculiaridades intrínsecas (quer à organização institucional, quer às celebrações por elas promovidas) como elemento contrastante e diferenciador entre entidades aparentemente semeIhantes e congêneres. Assim é também que, por exemplo, na reconstituição dos quadros sociais de irmandades e confrarias tem-se podido verificar os diferentes assenhoramentos que tribos e nações africanas fizeram da religião católica como condição de sobrevivência e/ou de ressurreição de expressões religiosas originariamente africanas. Assim é que, por exemplo, sempre apoiados na Antropologia e na Etnologia, afloram nesses estudos as distinções entre candomblés e macumbas, por comparação com reisados e congados. Distinções essas, saliente-se, que não dizem respeito apenas aos grupos étnicos realizadores das celebrações, mas também aos espaços geográficos diferenciados em que estes se expressa(ra)m.

Sendo as irmandades e associações congêneres dos poucos espaços de sociabilidade permitidos e, às vezes, emulados pela Metrópole na Colônia, no que respeita à população negra e mulata e, por decorrência, dadas sua proliferação e disseminação, é natural que elas também se apresentem como objeto privilegiado pela recente historiografia brasileira sobre o período colonial. No conjunto dessa produção, é possível identificar temas merecedores de especial afeição pelos estudiosos. É de se destacar que tópicos de cunho devocional ganharam realce na opção pelos objetos das pesquisas.

O mesmo acontece com os rituais praticados pelas irmandades, temática que, nos últimos anos, vem galvanizando as atenções dos pesquisadores. Para não me estender demasiado, limito-me a destacar dentre esses vários campos, os textos sobre celebrações associadas à morte, inclusive na faceta lúdica expressa nas pompas dos cortejos fúnebres e nos sepultamentos. Nesse horizonte, o trabalho de João J. Reis, embora não tendo como escopo a fase colonial, é obra de referência incontornável e inspiradora de estudos. Nela se demonstra a centralidade que as festas tinham no seio daquelas agremiações, permitindo ao autor conceber os ritos fúnebres como forma de "carnavalização (negra e branca) da religião católica” (REIS, J.J., 1991; cf. também CAMPOS, A. A., 1987 e 1994; EUGÊNIO, A., 2000; GAETA, M.A.J.V., 1992).

A insistir que o ludismo foi traço característico e vigoroso das irmandades coloniais brasileiras que não se restringiu às cerimônias fúnebres. Estendia-se a outras celebrações, inclusive como fator de emulação das rivalidades e antagonismos que vicejavam entre aqueles sodalícios. Assim, as solidariedades e as sociabilidades eram impulsionadas e se solidifica- 
vam tendo como força motriz a vontade coletiva de superação recíproca do brilho e a afirmação do prestígio social disputado pelos indivíduos e pelas associações por eles criadas e mantidas. Na Colônia, as igrejas e outros lugares de culto e celebrações eram igualmente (se não principalmente) espaços de convívio social onde religiosidade e sociabilidade se (con)fundiram e se interpenetraram.

Sem esquecer a condição das festas como local de (re)criação e de (re)afirmação de culturas e identidades africanas. Por conseguinte, enquanto a historiografia anterior ao período ora tratado tendeu para estudar as irmandades (terminologia genérica, ora adotada por comodidade expositiva), na sua individualização ou na sua faceta institucional, outras também têm sido agora as ênfases e as problemáticas trabalhadas: do papel político dessas entidades e de sua inserção no processo político-administrativo colonial (BOSCHI, C.C., 1986) à análise de sua condição de espaço de organização étnica e de reprodução desses grupos (AGUIAR, M.M., 1993; SOARES, M.C., 2000, 2002; OLIVEIRA, A.J.M., 2002; QUINTÃO, A.A., 1997), de sua condição de espaços de sociabilidades onde "culturas em negociação" forjavam alteridades (BORGES, C.A.R.M., 1998) ou concebidas como "mecanismo de inversão hierárquica no contexto da sociabilidade confrarial negra do Brasil colonial". (AGUIAR, M.M., 1993, 2001). Importa salientar, além disso, que se dedicando a perceber as diferenciações étnicas, de raça e procedência da escravaria colonial brasileira, esses historiadores introduzem e se debatem com "indagações teóricas de diferentes ordens", do que vêm resultando não desprezíveis contributos. (SOARES, M.C., 2000, p.26)

Por último, observe-se que a absoluta preponderância, quase que exclusividade, das pesquisas sobre as irmandades coloniais brasileiras se concentram naquelas que foram criadas e promovidas por negros e mulatos. São raros, na atual historiografia brasileira, os estudos dedicados às associações laicas de brancos, dentre as quais, as ordens terceiras, ainda não foram merecedoras da atenção que lhes é devida, ressalvadas pesquisas essencialmente monográficas que quase nunca ultrapassam a condição de repertórios de transcrição documental.

Tema afim (se não integrado) a este é o que se refere às Misericórdias. Apesar da saliência atribuída pela historiografia concernente ao império colonial português para o estudo do mutualismo e das Santas Casas, sob a ótica de espaços de sociabilidades, no caso do Brasil Colonial tais trabaIhos têm tido caráter predominantemente, para não dizer exclusivamente, monográfico. Ainda assim de qualidade bastante irregular. Incomuns são os trabalhos que se aproximam do nível encontrado na cuidada tese de Russell-Wood sobre a Misericórdia da Bahia (RUSSELL-WOOD, A.J.R. 1968, 1981). Também nessa temática a rarefação é marcante, como inexistentes são as análises comparativas. A registrar, contudo, exaustivo mapeamento das fontes primárias sobre tais entidades, buscando abarcar todo o terri- 
tório brasileiro, resultante da iniciativa da Pontifícia Universidade Católica de São Paulo, em projeto coordenado pela Profa . Dra . Yara Aun Khoury, já concluído e em processo de edição. Oxalá, o louvável empreendimento venha estimular o apetite dos historiadores brasileiros!

Retornemos, no entanto, à aliciante e prolífera temática das festas, para distinguir o trabalho de uma nossa companheira nessas IX Jornadas, citando a tese de Doutorado de Marina de Mello e Souza, publicada sob o título de Reis negros no Brasil escravista: história da festa de coroação de Rei Congo. Trata-se de importante contributo para os estudos relativos à festa como espaço de sociabilidade e de revitalização dos padrões culturais africanos no mundo colonial brasileiro.

A dupla formação acadêmica da autora, em Antropologia e em História, levaram-na a dedicar-se às pesquisas sobre as africanidades em suas interpenetrações com os estudos históricos. Pesquisas oportunas, porquanto coincidentes com a introdução da História da África, como disciplina, no currículo das escolas secundárias brasileiras. Fato esse que, por seu turno, tem propiciado a divulgação de bibliografia especializada na temática, na qual alguns autores, para além dos já referidos, vêm merecidamente se destacando, pela densidade e consistência de suas investigações ou pela agudeza e originalidade de suas interpretações (ALENCASTRO, L.F., 2000; FLORENTINO, M.G., 1995; SILVA, A. da C.I., 1992, 2002, 2003; SLENES, R., 1999).

Estudo da reelaboração ou da reconstrução das identidades básicas dos negros africanos das comunidades de escravos no Brasil-Colônia, através da análise das festas constituintes dos reinados e das congadas, no Reis negros, Marina lida "não apenas com a diversidade interna aos grupos de africanos, [...] mas com a diversidade radical das culturas européias dos colonizadores" (MELLO E SOUZA, M. de. op.cit., p. 154).

Ao analisar as eleições de reis negros e os rituais festivos que a elas eram inerentes, a autora torna-se, assim, caudatária de questões que, há tempos, tinham sido apontadas por Fernando Novais e que vêm sendo também objeto de pesquisas, dentre outros historiadores, de João Reis e Mariza de Carvalho Soares.

Vale assinalar ainda que estudos como os de Marina se conjugam com aqueles que têm procurado demonstrar as peculiaridades e a condição sociopolítica das festas e rituais da cultura afro-brasileira. É o que se verifica em trabalhos sobre os supra referidos congados, entendidos como inte(g)ração lúdica, como sistema ritual lúdico que, expresso fundamentalmente através de festas religioso-profanas, configura-se (também) como manifestação de resistência cultural (SILVA, R.A.da.,1999).

A par disso, confraternizações como os batuques, os calundus, os candomblés, os congados e os reinados, ao lado de importantes celebrações próprias às populações negras das zonas rurais aguardam estudos da 
lavra de historiadores. Quando realizados, certamente haverão de indicar as notórias especificidades existentes entre as práticas de sociabilidade desenvolvidas em distintos espaços geográficos, segmentos e grupos sociais e momentos históricos.

Em outro quadrante e tratando de outra população, registre-se a original pesquisa desenvolvida por Ronaldo Vainfas sobre a religiosidade e o sincretismo religioso no interior da sociedade e do espaço aborígenes. Estou me referindo às chamadas santidades, para usar termo de época, isto é, a rituais festivos, com cunho idolátrico, de religiosidade ameríndia, tendo como foco o mais conhecido — até agora — daqueles fenômenos na América portuguesa, ocorrido em Jaguaribe, no sul do Recôncavo baiano, no último lustro do século XVI (VAINFAS, R., 1995).

Novamente aqui se observa a assimilação que a moderna historiografia brasileira tem praticado relativamente ao aparato teórico-metodológico da Antropologia e da Etnografia, visto que o fio condutor do livro de Vainfas é a compreensão do milenarismo em geral e da idolatria insurgente e culturalmente híbrida em particular, características do fenômeno por ele focado e interpretado como expressão "da resistência social e cultural dos ameríndios em face do colonialismo".

Nessa hora em que a historiografia especializada vem se dedicando ao estudo das identidades, mais do que necessária, torna-se adequada a análise das diferenças e singularidades existentes nas multiformes sociabilidades e nas suas variadas expressões no Brasil Colonial.

Nesse sentido, analisar os espaços de sociabilidade e as identidades (a construção de identidades) de negros, afro-descendentes e de mestiços nos séculos XVIII e XIX, tomando como referenciais as relações familiares, a religiosidade e as rebeliões escravas e conflitos, tem sido o propósito de um grupo de jovens historiadores, que, em seus mestrados e doutorados, produziram textos de inegável qualidade. Exemplo desses grupos é o que se forma sob a coordenação de Maria Tereza Pereira Cardoso, no curso de História da recém-instituída Universidade Federal de São João Del Rei. Esses autores se perfilam na perspectiva de Sidney Chalhoub, em Visão da liberdade (1990), isto é, propõem-se "recuperar a subjetividade do elemento negro diante do sistema escravista, procurando fugir a estereótipos simplificadores".

Na realidade, esse viés historiográfico de se analisarem as múltiplas identidades sociais daquele majoritário e heterogêneo segmento e de se compreenderem os negros cativos como agentes, ou seja, como elementos ativos na formação da sociedade brasileira, advém de pesquisas sobre a história das famílias escravas, em especial sobre as relações intrafamiliares na população cativa do Brasil oitocentista, desenvolvidas por Robert Slenes (SLENES, R., 1999; BRÜGGER, S.M., 2002). 
Assinale-se também que, na Universidade Federal Fluminense, são desenvolvidas pesquisas sobre as identidades, que, voltadas para um sentido lato de difusão de seus resultados, discutem as formas de sua disseminação nas escolas de ensino secundário da História (ABREU, M.; SOIHET, R. 2003). A ter em conta, além disso, vertente historiográfica que, pautando-se por paradigmas da Antropologia, investiga e discute o cotidiano das famílias das populações escravas e suas relações familiares através dos laços de parentesco e de consangüinidade (DEL PRIORE, M. In: CARDOSO, C.F.; VAINFAS, R. 1997; SAMARA, E. M.1983, 2002;).

Das identidades às resistências as distâncias são mínimas. E assim é que alguns bons trabalhos vêm surgindo dentro da perspectiva de estudar outras formas de resistências e, portanto, de sobrevivência da sociabilidade entre os negros no Brasil Colonial, através das relações familiares, de parentesco e de vizinhança (DEL PRIORE, M. In: CARDOSO, C.F.; VAINFAS, R., 1997, p. 258). Ressalta-se que, parte dessas investigações é levada a cabo com base em fundos documentais que só agora começam a ser percorridos pelos historiadores, como sejam, por exemplo, os acervos formados por processos criminais (DIAS, M.O.L.S., apud MORAES, J.G.V. de; REGO, J.M., 2002, p. 204). Em alguns desses trabalhos, a originalidade não se reduz às fontes primárias escolhidas, como também aos espaços geográficos analisados e à abordagem adotada. É o que se lê em Fama pública: poder e costume nas Minas setecentistas, de Marco Antônio Silveira, que tem por objetivo o estudo, através dos libelos cíveis, das relações comunitárias nas áreas rurais, relações essas caracterizadas por distúrbios e tensões existentes na sociabilidade cotidiana.

A recuperação dos escravos como sujeitos históricos e estudos sobre a conexão entre violência, controle social e reprodução da ordem escravista foram o tema-objeto tratado por Sílvia $\mathrm{H}$. Lara em Campos da violência: escravos e senhores na capitania do Rio de Janeiro. Obra singular, por numerosas razões, seus ecos logo se fizeram notar tanto na influência sobre pesquisas que se lhe sucederam, como, em virtude da sua originalidade interpretativa, da polêmica historiográfica que dela adveio, em particular a que foi instalada por Jacob Gorender.

Rechaçando as tradicionais explicações bipolarizadas da sociedade escravista brasileira e a coisificação do escravo, Sílvia Lara, sem descurar das resistências, destacou os mecanismos e as estratégias de acomodação e de negociação praticadas pelos negros como forma de preservação de suas identidades. Essa mesma perspectiva pode ser lida em Negociação e conflito, de João Reis e Eduardo Silva (1989), ou nos trabalhos de Eduardo França Paiva, sobretudo em Escravidão e universo cultural da Colônia (2001).

Paralelamente a esse subcampo e dele muito próximas estão as investigações sobre antigos temas atinentes às sociabilidades e outras 
formas de resistência da população escrava negra. Indico, nessa medida, as pesquisas sobre os quilombos, examinados nos últimos tempos, dentre outras facetas, "enquanto contradições do escravismo" ou nas relações que mantiveram com os aglomerados urbanos que Ihes eram circunvizinhos, o que explica, pelo menos parcialmente, a longevidade que caracterizou inúmeras daquelas comunidades. A relevar, nessa seara, as pesquisas de Luciano Figueiredo sobre as vendas, atividades hegemonicamente de controle feminino, espaços multifacetados que, para além do inerente comércio, sediavam a prostituição, animavam a alcovitice e as festas coletivas, apresentando-se, além disso, como espaço de homizio. (FIGUEIREDO, L., 1993; cf. também DIAS, M.O.L. da S., 1984).

Ao mesmo tempo, a historiografia vem dando ciência da elástica dimensão geográfica e da proliferação desse fenômeno histórico, esboçando tipologia e diferenças entre eles, esquadrinhando mais cuidadosamente os laços de solidariedade e de sociabilidade construídos no seu interior, ademais de romper com tradição historiográfica que fazia crer tratarem-se os quilombos de empreendimentos típicos (ou quase restritos) à região Nordeste da Colônia. Nos avanços que a historiografia tem obtido nessa temática, enfatize-se a utilização por ela feita de estudos arqueológicos e de novas e diversificadas fontes primárias (GUIMARÃES, C.M., 1988; REIS, J.J.; GOMES, F.S., 1996; DEL PRIORE, M.; VENÂNCIO, R.P., 2001, 72-84).

A constatar também vasta e considerável produção historiográfica no Brasil, desenvolvida a partir dos anos 80, que, em termos genéricos e apenas para fazer-Ihes necessária menção, poder-se-ia denominar de História da Sexualidade, História da Família e História da Mulher no período colonial. Trata-se, sim, de produção orientada e sugerida pela matriz foucauldiana, mas cujo ponto de partida e inspiração é a releitura crítica de Gilberto Freyre, em particular de sua Casa Grande e Senzala (DEL PRIORE, M., 1997, 2000, 2001; ENGEL, M.,1997; FARIA, S.de.C., 1997, 1998; SILVA, M.B.N.da.,2002; SOIHET, R., 1997).

$\mathrm{Na}$ apreciação desses trabalhos, depreende-se o quão iminente os seus autores estiveram de efetuarem análises interpretativas que, uma vez ampliadas ou verticalizadas, certamente poderiam ser estendidas à compreensão das formas e dos espaços da sociabilidade daquela fase da história brasileira. Prova disto é que a documentação inquisitorial, das visitas diocesanas, e dos libelos e dos processos criminais, compulsada por esses historiadores tangencia e, por vezes, concorrem para tais estudos.

Se tal não resultou, outra assertiva que corrobora essa hipótese é a de se verificar que significativa parte dos historiadores que nela transitaram ou que nela permanecem pesquisando convergem seus interesses para estudos respeitantes à História do cotidiano e da vida privada.

O instrumental teórico-metodológico de que lançam mão e a intimidade por eles revelada no emprego de dilatada gama de fontes primárias 
facultar-Ihes-ia, com certa facilidade, encaminharem-se para o estudo dos espaços de sociabilidades, perspectiva essa que, auguremos, ainda se possa cumprir.

Diante de apreciável produção historiográfica sobre a História de Gênero no Brasil Colonial, que, dadas as limitações deste texto, restrinjo-me simplesmente a apontar (cf. DEL PRIORE, M., 1997), refiram-se a trabalhos em que os espaços de sociabilidades foram objeto de tratamento mais detido. É o que se dá, por exemplo, com algumas obras sobre a sociabilidade cultivada pelas mulheres e sobre a reclusão feminina, sobretudo aquela configurada nos recolhimentos e conventos (ALGRANTI, L.M., 1993; NASCIMENTO, A.A.V., 1994; SILVA, M.B.N.da., 2002).

Sobre isso, considere-se que a abordagem dessa temática tem sido marcada por "verdadeira revolução documental, pela redescoberta da pesquisa em arquivos", no contexto do que já se denominou historiografia da transgressão, tendo em conta a busca, pelos estudiosos, "de práticas que se desviavam da norma no campo dos amores e do imaginário" (DEL PRIORE, M., 2001, p. 226-227).

O tema-objeto dessas Jornadas induz-nos, quase que instintivamente, a vinculá-lo aos estudos históricos sobre a chamada privacidade. É para esse campo que agora me dirijo. A versão brasileira da História da Vida Privada, como de resto as suas homólogas, é obra em que os espaços de sociabilidades se constituem (implicitamente ou não) em objetos de análise. Nesta coleção, vinda à luz a partir de 1997 e dirigida por conhecido especialista na História luso-brasileira, o período colonial ocupa o primeiro dos quatro volumes. No Prefácio, Fernando Novais discute o conceito de vida privada, ou melhor, historiciza o conceito, destacando seus obstáculos, suas idiossincrasias e a singularidade pretendida no projeto editorial sob sua responsabilidade. Conforme destaca, por vezes, a despeito da polissemia terminológica, para a realidade histórica em foco, tanto se observa uma hipertrofia da vida privada como uma invasão de espaços, vale dizer: "o que é aparentemente público por natureza, converte-se em privado"(NOVAIS, F.A. In: MELLO E SOUZA, L.de, 1997, p. 9).

Por se propor como trabalho original - que se inspira, mas não se amolda à matriz francesa — , a História da Vida Privada no Brasil procurou obter coesão interna em cada volume, a partir de discussões freqüentes e regulares entre o editor, o diretor da coleção e os colaboradores. Conseqüentemente, subordinando-se ao projeto global da obra, cada texto foi objeto de avaliação coletiva, sujeitando-se a eventuais reformulações. Nas palavras do seu diretor, "nosso livro não tem artigos; tem capítulos. É uma concepção unitária" (cf. NOVAIS, F.; MELLO E SOUZA, L. de., 1997. p. 13).

Porém, não obstante o enorme sucesso editorial, os objetivos anunciados nem sempre resultaram exitosos, gerando críticas e reparos de consistência nada desprezíveis (cf. ARRUDA, J.J.; TENGARRINHA, J.M., 
1993.p.103-105; DE DECCA, E. apud MORAES, J.G.V de; REGO, J.M., 2002, p.285; PETERSEN, S.R.F., 1992;).

Finalizo essas anotações com a menção a um tipo de sociabilidade que vicejou em vários dos principais núcleos urbanos da Colônia, sobretudo no Setecentos. Espaços para deleite das elites letradas sem que as discussões que nelas se travaram e os estudos por elas produzidos ecoassem no conjunto do corpo social da Colônia, as academias coloniais brasileiras se apresentavam sob variado formato e composição social.

Elas possuíam caráter permanente, temporário ou ocasional (CANDIDO, A., 1959; CASTELO, J.A.,1978; CANDIDO, A.; CASTELO, J.A. 1966) e se compunham de grupos restritos, sendo promovidas por interesses e motivações momentâneas, ao tempo em que reuniam conjuntos ecléticos de membros.

Academias literárias e sociedades literárias foram nomenclaturas distintas para qualificar instituições de momentos e natureza próprias. Eram espaços de sociabilidades consentidos e, em certos casos, estimulados ou, opostamente, cerceados pela Metrópole. A primeira categoria, as academias literárias, foi típica do período pombalino; a segunda, as sociedades, características do final e da viragem do Dezoito, no que Antonio Candido consagrou como sendo fase de laicização da inteligência na realidade coIonial brasileira (CANDIDO, A., 1959; SILVA, M.B.N. da, 1999).

Atente-se, no entanto, para o fato de que os estudos produzidos sobre o tema, em número e qualidade incompatíveis com a sua relevância social, pouca atenção têm merecido dos historiadores propriamente ditos. Do que se conhece, o fundamental é produto do trabalho de críticos e historiadores da literatura (ÁVILA, A., 1967; CANDIDO, A., 1959; CASTELO, J.A., 1978; MARTINS, W., 1992). Para o período em pauta, no entanto, citem-se as teses de Doutorado defendidas pelos historiadores Afonso Carlos Marques dos Santos e Íris Kantor, bons exemplos de pesquisa documentais e bibliográficas a que se aliam agudas e penetrantes interpretações. Marques dos Santos estuda em No rascunho da nação: Inconfidência no Rio de Janeiro o ideário libertário e os projetos políticos dos intelectuais participantes da Sociedade Literária do Rio de Janeiro, em fins do Dezoito; Kantor, em De Esquecidos e Renascidos: historiografia acadêmica luso-americana (1724-1759), analisa a vocação historiográfica de duas das "academias brasílicas", através da prática de sociabilidade intelectual corporativa por elas desenvolvidas.

Minhas últimas palavras orientam-se para vários espaços de sociabilidade do período colonial brasileiro cuja relevância é freqüentemente apregoada pelos autores, que, no entanto, reclama a elaboração de simples estudos monográficos, requisito para sua apreciação sintética e global.

Numerosos exemplos poderiam ser evocados. Fiquemos em alguns poucos. As romarias e peregrinações; os saraus ou tertúlias literárias (am- 
bientes de sociabilidades restritivas); a freqüência às casas de jogos e de alcouce, às praças de touros; as cavalhadas, sobretudo aquelas promovidas pela população branca, eventos "de gente rica para embevecer e impressionar o populacho" (ARAÚJO, E., 1993, p.140), dos quais se tem notícia desde, pelo menos, a presença holandesa no Nordeste da Colônia (TINHORÃO, J.R., 2000, p. 60 e seg.); a freqüência às danças em espaços públicos e aos entrudos e até mesmo às bibliotecas que, em sendo particulares, eram disponibilizadas para consulta, pública, como foram as de certos colégios jesuítas ou a que possuía o bispo de São Paulo, D.fr.Manuel da Ressurreição (1772-1789).

Faltam pesquisas sobre as sociabilidades vivenciadas nos teatros coloniais, sobretudo nos do século XVIII. Na altura, não mais cumprindo a função pedagógica que caracterizava os autos representados nos recintos fechados dos primeiros tempos coloniais, as encenações também ganharam as praças e se mundanizaram. Os atores e as troupe tornaram-se itinerantes. Novos espaços, outros públicos, sociabilidades peculiares; enfim, novos estilos de vida (ARAÚJO, E., 1993, p.142-146).

Agora, efetivamente, ponho o ponto final. O Brasil de 2003 é todo domínio da esperança e de acesso para boas perspectivas. Tomara que esses sentimentos prevaleçam e que também se instalem no seu panorama historiográfico!

\section{REFERÊNCIAS BIBLIOGRÁFICAS}

ABREU, Martha; SOIHET, Rachel, org. Ensino de História: conceitos, temáticas e metodologia. Rio de Janeiro: Casa da Palavra, 2003.

AGUIAR, Marcos Magalhães de. Vila Rica dos confrades: a sociabilidade confrarial entre negros e mulatos no século XVIII. São Paulo: Universidade de São Paulo, 1993. Dissertação de Mestrado. (Policopiada).

AGUIAR, Marcos Magalhães de. Negras Minas Gerais: uma história da diáspora africana no Brasil Colonial. São Paulo: Universidade de São Paulo, 1999. Tese de Doutorado. (Policopiada).

AGUIAR, Marcos Magalhães de. Festas e rituais de inversão hierárquica nas irmandades negras de Minas colonial. In: JANCSÓ, Stan; KANTOR, Iris, org. Festa: cultura e sociabilidade na América portuguesa. São Paulo: Hucitec: EDUSP: FAPESP: Imprensa Oficial, 2001, p.361-396.

ALENCASTRO, Luiz Felipe de. O trato dos viventes: formação do Brasil no Atlântico Sul. São Paulo: Companhia das Letras, 2000.

ALGRANTI, Leila Mezan. Honradas e devotas: mulheres da Colônia - condição feminina nos conventos e recolhimentos do Sudeste do Brasil; 1750-1822. Rio de Janeiro: José Olympio; Brasília: Edunb, 1993.

ARAÚJJO, Emanuel. O teatro dos vícios: transgressão e transigência na sociedade urbana colonial. Rio de Janeiro: José Olímpio, 1993.

ARRUDA, José Jobson; TENGARRINHA, José Manuel. Historiografia luso-brasileira contemporânea. Bauru: EDUSC, 1999. 
ARRUDA, José Jobson; FONSECA, Luís Adão da, org. Brasil-Portugal: História, agenda para o milênio. Bauru: EDUSC; São Paulo: FAPESP; Portugal, PT: ICCTI, 2001.

ÁVILA, Affonso. Resíduos seiscentistas em Minas: textos do século do ouro e as projeções do mundo barroco. Belo Horizonte: UFMG/Centro de Estudos Mineiros, 1967. 2v.

BEZERRA, Holien Gonçalves, coord. Quem é quem na História: pesquisadores e pesquisas no Brasil. Goiânia: CEGRAF/ANPUH-CNPq, 1996.

BORGES, Célia Aparecida R. Maia. Devoção branca de homens negros: as irmandades do Rosário em Minas Gerais no século XVIII. Niterói: Universidade Federal Fluminense, 1998. Tese de Doutorado. (Policopiada).

BOSCHI, Caio C. Os leigos e o poder: irmandades leigas e política colonizadora em Minas Gerais. São Paulo: Ática, 1986.

BOSCHI, Caio C. Produção historiográfica universitária e sua difusão: Brasil, 1982-1989. Amar, sentir e viver a História: estudos de homenagem a Joaquim Veríssimo Serrão. Lisboa: Colibri, 1995. v.1, p.261-274.

BOSCHI, Caio C. A pós-graduação em História no Brasil nos anos 80. Fraternidade e abnegação: a Joaquim Veríssimo Serrão, os amigos. Lisboa: Academia Portuguesa de História, 1999. v.1, p.167-182.

BRÜGGER, Sílvia M. Minas patriarcal: família e sociedade-São João Del Rei, séculos XVIII e XIX. Niterói: Universidade Federal Fluminense, 2002. Tese de Doutorado. (Policopiada).

CAMPOS, Adalgisa A. Considerações sobre a pompa fúnebre na capitania de Minas: o século XVIII. Revista do Departamento de História da UFMG, 1987, nº. 4, p.3-24.

CAMPOS, Adalgisa A. A terceira devoção do Setecentos:o culto a São Miguel e Almas. São Paulo: Universidade de São Paulo, 1994. Tese de Doutorado. (Policopiada).

CANDIDO, Antonio. Formação da literatura brasileira (momentos decisivos). São Paulo: Martins, 1959. 2v.

CANDIDO, Antonio; CASTELLO, José Aderaldo. Presença da literatura brasileira. 2 ed. São Paulo: Difusão Européia do Livro, 1966. (v.1 - Das origens ao Romantismo).

CAPELATO, Maria Helena R., coord. Produção histórica no Brasil: 1985-1994: Catálogo de dissertações e teses dos programas e cursos de pós-graduação em História. São Paulo: Xamã, 1995. 3v.

CARDOSO, Ciro F.; VAINFAS, Ronaldo, org. Domínios da História: ensaios de teoria e metodologia. Rio de Janeiro: Campus, 1997.

CASTELO, José Aderaldo, org. O movimento academicista no Brasil, 1641-1820/22. São Paulo: Conselho Estadual de Cultura, 1978.

CASTRO, Hebe. História Social. In: CARDOSO, Ciro F.; VAINFAS, Ronaldo, org. Domínios da História: ensaios de teoria e metodologia. Rio de Janeiro: Campus, 1997. p. 45-59.

CHALHOUB, Sidney. Visões da liberdade: uma história das últimas décadas da escravidão na corte. São Paulo: Companhia das Letras, 1990.

COUTO, Jorge. Brasil. In: MATOS, Artur Teodoro de; THOMAZ, Luiz Filipe F. Reis, dir. Vinte anos de historiografia ultramarina portuguesa (1972-1992). Lisboa: Comissão Nacional para as Comemorações dos Descobrimentos Portugueses, 1993, p.97-122.

DEL PRIORE, Mary. Festas e utopias no Brasil Colonial. São Paulo: Brasiliense, 1994

DEL PRIORE, Mary, org. História das mulheres no Brasil. São Paulo: Contexto, 1997.

DEL PRIORE, Mary. História do cotidiano e da vida privada. In: CARDOSO, Ciro F.; VAINFAS, Ronaldo, org. Domínios da História: ensaios de teoria e metodologia. Rio de Janeiro: Campus, 1997. p. 259-274.

DEL PRIORE, Mary. A família no Brasil Colonial. São Paulo: Moderna, 2000.

DEL PRIORE, Mary. História das mulheres: as vozes do silêncio. In: FREITAS, Marcos Cézar, org. Historiografia brasileira em perspectiva, 4 ed. São Paulo: Contexto, 2001. p.217-235.

DEL PRIORE, Mary; VENÂNCIO, Renato Pinto. O livro de ouro da História do Brasil. Rio de Janeiro: Ediouro, 2001. 
DIAS, Maria Odila Leite da Silva. Quotidiano e poder em São Paulo no século XIX. São Paulo: Brasiliense, 1984.

DIAS, Maria Odila Leite da Silva. Sociabilidades sem História: votantes pobres do Império, 1824-1881. In: FREITAS, Marcos Cézar, org. Historiografia brasileira em perspectiva. 4 ed. São Paulo: Contexto, 2001. p.57-72.

ENGEL, Magali. História e sexualidade. In: CARDOSO, Ciro F; VAINFAS, Ronaldo, org. Domínios da História: ensaios de teoria e metodologia. Rio de Janeiro: Campus, 1997. p. 297-311.

Estudos Históricos, Rio de Janeiro, FGV/CPDOC, nº. 28, 2001.

EUGÊNIO, Alisson. Reinvenção da existência: as festas devocionais das irmandades negras no século XVIII mineiro. Rio de Janeiro: Universidade Federal do Rio de Janeiro, 2000. Dissertação de Mestrado. (Policopiada).

FALCON, Francisco J.C. Historiografia portuguesa contemporânea: um ensaio histórico-interpretativo. Estudos Históricos, Rio de Janeiro, FGV/CPDOC, nº.1, 1988, p.79-99.

FALCON, Francisco J.C. A identidade do historiador. Estudos Históricos, Rio de Janeiro, FGV/CPDOC, v.9, no.17, 1996. p.7-30.

FALCON, Francisco. História e poder. In: CARDOSO, Ciro F.; VAINFAS, Ronaldo, org. Domínios da História: ensaios de teoria e metodologia. Rio de Janeiro: Campus, 1997. p. 61-89.

FARIA, Sheila de Castro. História da família e demografia histórica. In: CARDOSO, Ciro F.; VAINFAS, Ronaldo, org. Domínios da História: ensaios de teoria e metodologia. Rio de Janeiro: Campus, 1997. p. 127-162.

FARIA, Sheila de Castro. A Colônia em movimento: fortuna e família no cotidiano colonial. Rio de Janeiro: Nova Fronteira, 1998.

FENELON, Déa R. O historiador e a cultura popular: história de classe ou história do povo? História \& Perspectivas, Uberlândia, UFU, no.6, jan./jun. 1992, p.5-23.

FICO, Carlos; POLITO, Ronald. A História no Brasil (1980-1989): elementos para uma avaliação historiográfica. Ouro Preto: UFOP, 1992, v.1.

FICO, Carlos; POLITO, Ronald. Teses e dissertações de História defendidas em 1995. Estudos Históricos, Rio de Janeiro, FGV/CPDOC, v.9, n.17, 1996. p.167-176.

FIGUEIREDO, Luciano. O avesso da memória: cotidiano e trabalho da mulher em Minas Gerais no século XVIII. Rio de Janeiro: José Olympio; Brasília: Edunb, 1993.

FIGUEIREDO, Luciano. A revolta é uma festa: relações entre protestos e festas na América portuguesa. In: JANCSÓ, Stan; KANTOR, Iris, org. Festa: cultura e sociabilidade na América portuguesa. São Paulo: Hucitec: EDUSP: FAPESP: Imprensa Oficial, 2001, p.263-278.

FLORENTINO, Manolo Garcia. Em costas negras: uma história do tráfico atlântico de escravos entre a África e o Rio de Janeiro (séculos XVIII e XIX). Rio de Janeiro: Arquivo Nacional, 1995.

FREITAS, Marcos Cézar de, org. Historiografia brasileira em perspectiva. São Paulo: Contexto, 2001.

GAETA, Maria Aparecida Junqueira V. O escravo nas praças: a festa religiosa das confrarias do Brasil no século XVIII. Lisboa: Universitária, 1992.

GUIMARÃES, Carlos Magno. A negação da ordem escravista: quilombos em Minas Gerais no século XVIII. São Paulo: Ícone, 1988.

JANCSÓ, István; KANTOR, Iris, org. Festa: cultura e sociabilidade na América portuguesa. São Paulo: Hucitec: EDUSP: FAPESP: Imprensa Oficial, 2001. 2v.

KANTOR, Iris. Pacto festivo em Minas colonial. São Paulo: Unversidade de São Paulo, 1996. Dissertação de Mestrado. (Policopiada).

KANTOR, Iris. De Esquecidos e Renascidos: historiografia acadêmica luso-americana (17241759). São Paulo: Universidade de São Paulo, 2002. Tese de Doutorado. (Policopiada)

LAPA, J.R. do Amaral. História e historiografia: Brasil pós-64. Rio de Janeiro: Paz e Terra, 1985.

LARA, Sílvia Hunold. Campos da violência: escravos e senhores na capitania do Rio de Janeiro, 1750-1808. Rio de Janeiro: Paz e Terra, 1988. 
LOUSADA, Maria Alexandre. Espaços de sociabilidade em Lisboa: finais do século XVIII a 1834. Lisboa: Universidade de Lisboa, 1995. Dissertação de Doutoramento. (Policopiada).

MALERBA, Jurandir. Em busca de um conceito de historiografia: elementos para uma discussão. Varia História, Belo Horizonte, UFMG, n² 27, jul. 2002, p. 27-47.

MARTINS, Wilson. História da inteligência brasileira. 4 ed. São Paulo: T.A. Queiroz, 1992. v.1 (1550-1794) e v.2 (1794-1855).

MELLO E SOUZA, Laura de, org. Cotidiano e vida privada na América portuguesa. São Paulo: Companhia das Letras, 1997. (Col. História da Vida Privada no Brasil, v.1).

MELLO E SOUZA, Laura de. Aspectos da historiografia da cultura sobre o Brasil Colonial. In: FREITAS, Marcos Cézar, org. Historiografia brasileira em perspectiva. 4 ed. São Paulo: Contexto, 2001. p. 17-37.

MELLO E SOUZA, Marina de. Reis negros no Brasil escravista: história da festa de coroação de Rei Congo. Belo Horizonte: Edit. UFMG, 2002.

MONTEIRO, Rodrigo Bentes. Entre festas e motins: afirmação do poder régio bragantino na América portuguesa (1690-1763). In: JANCSÓ, Stan; KANTOR, Iris, org. Festa: cultura e sociabilidade na América portuguesa. São Paulo: Hucitec: EDUSP: FAPESP: Imprensa Oficial, 2001, p.127-150.

MORAES, José Geraldo Vinci de; REGO, José Márcio. Conversas com historiadores brasileiros. São Paulo: Edit.34, 2002.

NASCIMENTO, Anna Amélia Vieira. Patriarcado e religião: as enclausuradas clarissas do convento do Desterro da Bahia, 1677-1890. Salvador: Conselho Estadual de Cultura da Bahia, 1994.

NOVAIS, Fernando A. A Universidade e a pesquisa histórica: apontamentos. Estudos Avançados, São Paulo, USP, v.4, no .8, jan./abr. 1990, p.108-115.

NOVAIS, Fernando A. Condições da privacidade na Colônia. In: MELLO E SOUZA, Laura, org Cotidiano e vida privada na América portuguesa. São Paulo: Companhia das Letras, 1997, p. 13-39. (Col. História da Vida Privada no Brasil, v.1).

NOVAIS, Fernando; MELLO E SOUZA, Laura de. A História de uma miragem. Folha de S. Paulo, São Paulo, 25 mai 1997, Cad. Mais, p.13.

OLIVEIRA, Anderson José M. de. Os santos pretos carmelitas: culto dos santos, catequese e devoção negra no Brasil Colonial. Niterói: Universidade Federal Fluminense, 2002. Tese de Doutorado. (Policopiada).

PAIVA, Eduardo França. Escravidão e universo cultural na Colônia: Minas Gerais, 1716-1789. Belo Horizonte: Edit. UFMG, 2001.

PETERSEN, Sílvia Regina F. Dilemas e desafios da historiografia brasileira: a temática da vida cotidiana. História \& Perspectivas, Uberlândia, UFU, no.6, jan./jun. 1992, p.25-44.

QUINTÃO, Antônia Aparecida. Lá vem o meu parente: as irmandades de pretos e pardos no Rio de Janeiro e Pernambuco. São Paulo: Universidade de São Paulo, 1997. Tese de Doutorado. (Policopiada).

REIS, João José. A morte é uma festa: ritos fúnebres e revolta popular no Brasil do século XIX. São Paulo: Companhia das Letras, 1991.

REIS, João José; GOMES, Flávio dos Santos, org. Liberdade por um fio: história dos quilombos no Brasil. São Paulo: Companhia das Letras, 1996.

REIS, João José; SILVA, Eduardo. Negociação e conflito: a resistência negra no Brasil escravista. São Paulo: Companhia das Letras, 1989.

RUSSELL-WOOD, A.J.R. Fidalgos and Philanthropists: the Santa Casa da Misericórdia of Bahia, 1550-1755. Berkeley: University of California Press, 1968. Trad. port. Fidalgos e Filantropos: A Santa Casa de Misericórdia da Bahia, 1550-1755. Brasília: Ed. UNB, 1981.

SAMARA, Eni Mesquita. A família brasileira. São Paulo: Brasiliense, 1983.

SAMARA, Eni de Mesquita. A Colônia em bibliografia recente (1970-1998). São Paulo: Humanitas/FFLCH/USP, 1999. 
SAMARA, Eni de Mesquita. Historiografia brasileira em debates: olhares, recortes e tendências. São Paulo: Hermanitas/FFLCH-USP, 2002.

SANTOS, Afonso Carlos Marques dos. No rascunho da nação: Inconfidência no Rio de Janeiro. Rio de Janeiro: SMCTE/DGDIC/Div. de Editoração, 1992.

SANTOS, Beatriz Catão Cruz. O corpo de Deus na América: a festa de Corpus Christi nas cidades da América portuguesa — século XVIII. Niterói: Universidade Federal Fluminense (UFF), 2001. Tese de Doutorado em História.

SILVA, Alberto da Costa e. A enxada e a lança: a África antes dos portugueses. Rio de Janeiro: Nova Fronteira, 1992.

SILVA, Alberto da Costa e. A manilha e o libambo: a África e a escravidão, de 1500 a 1700. Rio de Janeiro: Nova Fronteira: Fundação Biblioteca Nacional, 2002.

SILVA, Alberto da Costa e. Um rio chamado Atlântico: a África no Brasil e o Brasil na África. Rio de Janeiro: Nova Fronteira: Ed. UFRJ, 2003.

SILVA, Marcos, org. Dicionário crítico Câmara Cascudo. São Paulo: Perspectiva, FFLCH/USP, FAPESP; Natal: EDUFRN, Fundação José Augusto, 2003.

SILVA, Maria Beatriz Nizza da. A cultura luso-brasileira: da reforma da Universidade à independência do Brasil. Lisboa: Estampa, 1999. (Histórias de Portugal, 43).

SILVA, Maria Beatriz Nizza da. Donas e plebéias na sociedade colonial. Lisboa: Estampa, 2002. (Histórias de Portugal, 50).

SILVA, Rubens Alves da. Negros católicos ou catolicismo negro? Um estudo sobre a construção da identidade negra no congado mineiro. Belo Horizonte: Universidade Federal de Minas Gerais, 1999. Dissertação de Mestrado. (Policopiada).

SILVEIRA, Marco Antônio. Fama pública: poder e costume nas Minas setecentistas. São Paulo: Universidade de São Paulo, 2000. Tese de Doutorado. (Policopiada)

SLENES, Robert. Na senzala uma flor: as esperanças e as recordações na formação da família escrava - Brasil Sudeste, século XIX. Rio de Janeiro: Nova Fronteira, 1999.

SOARES, Mariza de Carvalho. Devotos da cor: identidade étnica, religiosidade e escravidão no Rio de Janeiro, século XVIII. Rio de Janeiro: Civilização Brasileira, 2000.

SOARES, Mariza de Carvalho. O império de São Elesbão na cidade do Rio de Janeiro, no século XVIII. Topoi, UFRJ, Rio de Janeiro, mar. 2002, p.59-83.

SOIHET, Rachel. História das mulheres. In: CARDOSO, Ciro F; VAINFAS, Ronaldo, org. Domínios da História: ensaios de teoria e metodologia. Rio de Janeiro: Campus, 1997. p. 275-296.

SCHWARTZ, Stuart B. Da América Portuguesa ao Brasil: estudos históricos. Lisboa: DIFEL, 2003.

TINHORÃO, José Ramos. As festas no Brasil Colonial. São Paulo: Edit.34, 2000.

TORGAL, Luís R.; MENDES, José A.; CATROGA, Fernando. História da História em Portugal, sécs. XIX-XX. [Lisboa]: Círculo de Leitores, 1996.

VAINFAS, Ronaldo. A heresia dos índios: catolicismo e rebeldia no Brasil Colonial. São Paulo: Companhia das Letras, 1995.

VAINFAS, Ronaldo. História das mentalidades e história cultural. In: CARDOSO, Ciro F.; VAINFAS, Ronaldo, org. Domínios da História: ensaios de teoria e metodologia. Rio de Janeiro: Campus, 1997. p. 127-162.

VAINFAS, Ronaldo. Caminhos e descaminhos da História. In: CARDOSO, Ciro F.; VAINFAS, Ronaldo, org. Domínios da História: ensaios de teoria e metodologia. Rio de Janeiro: Campus, 1997. p. 441-449.

VOVELLE, Michel. Dez anos de sociabilidade meridional. In: Ideologias e mentalidades. Trad. port. São Paulo: Brasiliense, 1987. p.225-239.

WEHLING, Arno et al. Tendências da historiografia brasileira contemporânea: uma aproximação preliminar. Anais do VII Congresso da Associação Iberoamericana de Academias de História. Rio de Janeiro: Instituto Histórico e Geográfico Brasileiro, 2000, p.491-553. 